\title{
MRS Establishes a Publishing Partnership with Cambridge University Press: A New Era Begins
}

I am pleased to announce that the Materials Research Society and Cambridge University Press have entered into an historic partnership, expanding print and electronic access to MRS current publications and collaborating on new communications at the forefront of materials research. As a member of MRS, you will begin to enjoy the benefits of this partnership effective January 2011, at which time MRS Bulletin, the Journal of Materials Research, and the Online Proceedings Library will have a new online look with greatly expanded functionality. These publications will be hosted as an MRS portal on Cambridge's cutting-edge electronic platform, Cambridge Journals Online. You will be able to access the MRS portal seamlessly through the MRS Web site.

Online publishing is dramatically changing the face of information access globally and has already impacted MRS's publications program. And the opportunities for serving the needs of authors and readers will continue to increase exponentially-including speed of publication, search sophistication, ancillary information, and advanced delivery mechanisms. MRS is a leader in delivering leading-edge materials research through its meetings and publications. We will continue to focus on this strength. Cambridge University Press's unparalleled international reach and mutual vision for service to the scientific and educational community positions MRS at the threshold of a new era for serving the materials community. The future will see expanded content for MRS publications, broader dissemination of cutting-edge materials information, and a

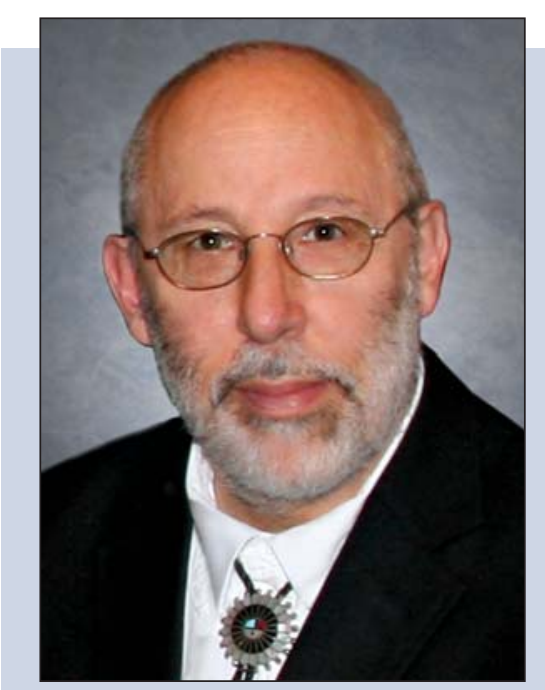

"Online publishing is dramatically changing the face of information access globally...."

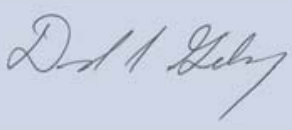

next generation of MRS education and outreach programs.

From the outset of the new communications platform in January 2011, MRS members will enjoy a number of new enhancements to MRS publications and services. But the changes won't stop there. Plans for ongoing improvements to the publications platform are already being mapped as well as new publications offerings, ranging from journals to "online only" content to books. We anticipate that the partnership will continue to evolve significantly over the next two to five years. In addition, MRS will launch an entirely new Web site in early 2011 to complement the publications portal and serve the growing meetings, outreach, professional services, and advocacy initiatives of the Society.

Many MRS volunteers have been working diligently over the past year on the future of MRS's publications portfolio, and their involvement has been critical to bringing MRS to this important juncture. Their work is a testament to how MRS volunteers are making a difference in the Society and the profession. This process began in 2009, engaging a number of task forces and culminating with the recommendation to partner with Cambridge University Press at the MRS Board of Directors' meeting held during the 2010 MRS Spring Meeting. Several additional task forces are currently developing greatly expanded future visions for MRS in the areas of news, technical information, and educational resources.

As exciting as this achievement will be for MRS and its members, it is only the first step. There is still much to do as we launch the new publications platform with Cambridge University Press in 2011. And this new partnership will allow us to do many things we have not yet anticipated. So I invite you, MRS members, to become engaged, leveraging our collective talents and moving the MRS Communications Portfolio into the future.

DAVID S. GINLEY 2010 MRS President

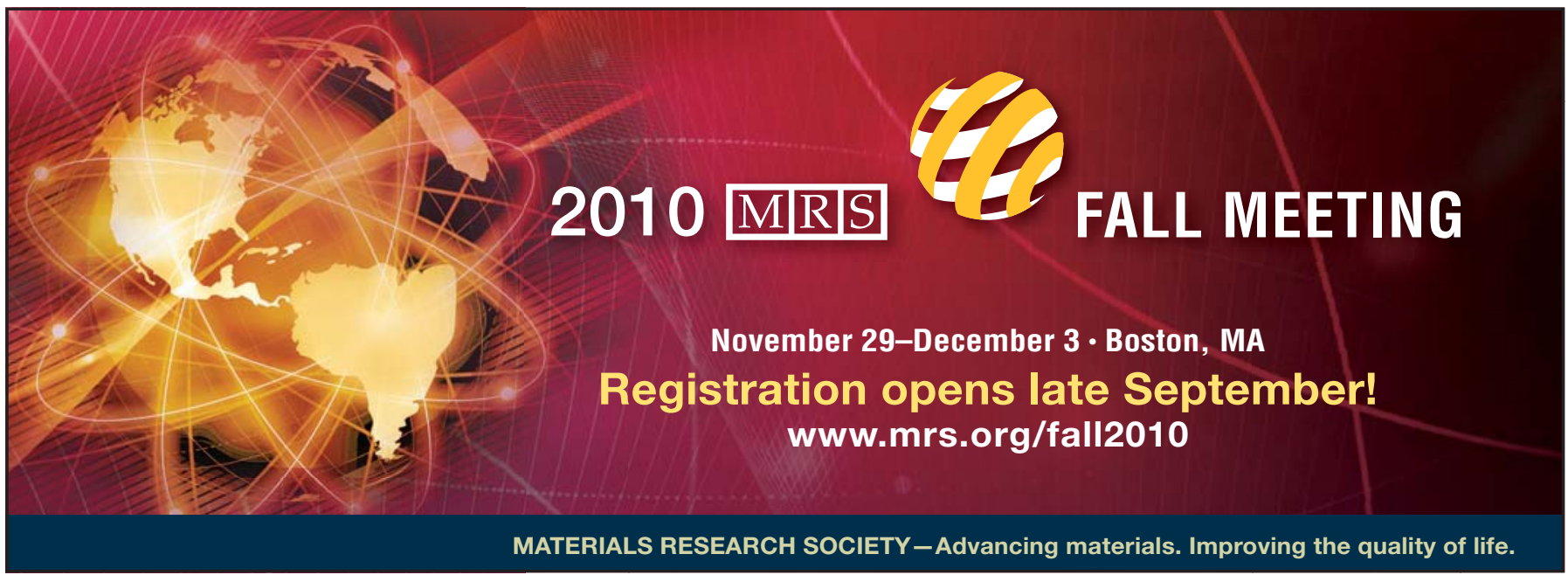

